\title{
Bioavailability of a New Oral Spray Melatonin Emulsion Compared with a Standard Oral Formulation in Healthy Volunteers
}

\author{
Antonella Natalia Bartoli ${ }^{1}$, Simona De Gregori ${ }^{1}$, Mariadelfina Molinaro ${ }^{1}$, Monica Broglia ${ }^{1}$, Carmine Tinelli ${ }^{2}$ and Roberto Imberti ${ }^{3}$ \\ ${ }^{1}$ Clinical Pharmacokinetics in Trasplantations and Autoimmune Diseases, Fondazione IRCCS Policlinico S.Matteo, Pavia, Italy \\ ${ }^{2}$ Clinical Epidemiology and Biometric Unit, Fondazione IRCCS Policlinico S.Matteo, Pavia, Italy \\ ${ }^{3}$ Direzione Scientifica, Fondazione IRCCS Policlinico S.Matteo, Pavia, Italy
}

\begin{abstract}
Background and Objective: Melatonin, a pineal gland hormone secreted at night, is involved in the sleep-wake cycle and has been extensively used in the treatment of primary sleeping disorders. Up to $90 \%$ of blood melatonin is cleared by the liver in a single passage, thus its half-life is very short (30-60 minutes). To avoid the first pass effect responsible for up to $90 \%$ loss of the melatonin oral dosage and to ensure rapid onset of activity, a new food grade liquid emulsion has been formulated in a spray form, which assures an additional increase of the contact surface and the possibility of efficient mucosal absorption.
\end{abstract}

The purpose of the present study was to investigate the bioavailability profile of this new food grade liquid emulsion compared with a standard melatonin formulation in commercially available oral tablets.

Methods: In a single-dose, open-label, crossover study, eight subjects were randomly assigned to receive 5 $\mathrm{mg}$ of oral spray or oral melatonin (tablet). After a washout of one week, plasma was collected at six hours post dosing and assayed by a validated liquid chromatography tandem mass spectrometry method to determine the main pharmacokinetic parameters.

Results and Discussion: The student $t$ Test for paired data highlighted a significant difference between $\mathrm{C}_{\mathrm{max}}$ values $(p=0.021)$ and the AUC $(p=0.045)$. The absorption rate $\left(T_{\max }\right)$ of the two melatonin formulations did not show statistically significant differences (Friedman test). The amount of melatonin reaching the systemic circulation after oral spray administration was significantly higher than after oral tablet administration.

Keywords: Melatonin; Bioavailability; Pharmacokinetics; Spray; Oral

\section{Introduction}

In recent years, sleep disturbances have been documented to affect up to thirty percent of the Western hemisphere's population. Depression, anxiety and stress are the most common causes of sleep disturbances related to sleep-onset and sleep-maintenance difficulties. Sleep disturbances are common in the elderly, apart from psychological causes; they may be caused by side effects of medication or disease [1].

Melatonin (N-acetyl-5-methoxytryptamine) is a circulating hormone produced by the pineal gland during the dark phase of the day-night cycle. It is involved in the sleep-wake cycle and synthetic melatonin preparations have been extensively used in the treatment of primary sleeping problems [2]. The secretion of melatonin markedly decreases [3], as sleep fragmentation increases with age [4].

Up to $90 \%$ of blood melatonin is cleared by the liver in a single passage, making its half-life very short (30-60 minutes). It is metabolized in the liver by hydroxylation to 6-hydroxymelatonin and excreted in the urine following conjugation with sulfuric or glucuronic acid. Melatonin, but not its sulphate metabolites, readily crosses the blood-brain barrier [5]. Only blue light, of around $480 \mathrm{~nm}$, suppresses the production of melatonin. Unfortunately, this type of light is present in many artificially lit environments [6]. The European Food Safety Authority (EFSA) has published guidelines on safety and efficacy in the use of melatonin, as a food supplement, at a dosage of 0.5-5 mg for the treatment of jet lag [7]. Melatonin has also been proposed as the standard agent for circadian rhythm sleep disorders, such as Delayed Sleep Phase Syndrome (DSPS) and non 24-hour sleep wake syndrome [8-10]. It can reduce sleep latency largely in patients with DSPS than in patients with insomnia and it is especially effective in the elderly, who present physiologically low blood levels of the hormone [11].

To avoid the first pass effect responsible for up to $90 \%$ loss of the oral melatonin dose and to ensure rapid onset of activity, a new food grade liquid emulsion (Melatonin in emulsion spray by Medestea SpA) has been formulated in a spray form with an additional increase of the contact surface and the possibility of efficient mucosal absorption. These affirmations have been confirmed in an in vitro permeability study with porcine cheek epithelium [12].

Therefore, a pharmacokinetic (PK) study was necessary to verify whether the delivery of a melatonin emulsion at the buccal mucosa truely improved the amount and the rate of melatonin absorption compared to a standard oral tablet formulation. Parameters of primary interest were pharmacokinetic variables determined in plasma: Area Under the Curve $\left(\mathrm{AUC}_{0-\infty}\right)$, peak plasma concentration $\left(\mathrm{C}_{\max }\right)$, Mean Residence Time (MRT), Time relative to the peak concentration $\left(\mathrm{T}_{\max }\right)$, elimination half-life $\left(\mathrm{T}_{1 / 2}\right)$.

*Corresponding author: Antonella Bartoli, Clinical Pharmacokinetics in Transplantations and Autoimmune Diseases, Foundation IRCCS Policlinico San Matteo, Piazzale Golgi n.2, 27100 Pavia, Pavia Italy, Tel: +39 0382503471 ; Fax: +390382 422701; E-mail: a.bartoli@smatteo.pv.it

Received August 23, 2012; Accepted September 20, 2012; Published Septembe 25, 2012

Citation: Bartoli AN, De Gregori S, Molinaro M, Broglia M, Tinelli C, et al (2012) Bioavailability of a New Oral Spray Melatonin Emulsion Compared with a Standard Oral Formulation in Healthy Volunteers. J Bioequiv Availab 4: 096-099. doi:10.4172/jbb.1000120

Copyright: ( 2012 Bartoli AN, et al. This is an open-access article distributed under the terms of the Creative Commons Attribution License, which permits unrestricted use, distribution, and reproduction in any medium, provided the original author and source are credited. 


\section{Methods}

\section{Subjects}

The study was carried out in accordance with the principles of the current revision of the Declaration of Helsinki and its amendments; the International Conference Guidelines for Good Clinical Practices and local legal and regulatory requirements. The Ethics Committee of the Fondazione IRCCS Policlinico San Matteo Hospital approved the study protocol.

Before enrollment in the study, subjects were fully informed of the aim, methods, expected study duration, anticipated risks and possible discomfort and afterwards, written informed consent was obtained.

Eight healthy volunteers (five males, three females) aged between 21 and 51 years were included based on their medical history, clinical and physical examinations, vital signs, biological tests and electrocardiogram (ECG). In particular, renal and hepatic functions were normal in all volunteers, and no clinically relevant abnormal laboratory values or relevant clinical abnormalities were observed during the screening phase. Exclusion criteria included the presence or history of any significant disease, alcohol and/or drug abuse, smoke abuse, positive HIV and/or Hepatitis B and C test. No concomitant therapy was permitted. Female patients of childbearing age were excluded if not using or if not willing to continue using a medically reliable method of contraception for the entire study duration. Any concomitant assumption of products containing melatonin or derivate inhibitors and inductors of CYP450 were not allowed during the study period. Patients treated with any investigational study medication or who underwent any medical procedure in the previous 90 days were excluded.

\section{Study design and clinical procedures}

This open-label, randomized crossover study was designed to investigate $5 \mathrm{mg}$ doses of the oral melatonin formulation (Melatonin in emulsion spray by Medestea SpA, $1 \mathrm{mg}$ of melatonin for each spray and Melatonin tablet containing $5 \mathrm{mg}$ of melatonin manufactured by SIRC). During scheduled visits, the investigator dispensed $5 \mathrm{mg}$ (5 sprays of a food grade liquid emulsion directly under the tongue) of melatonin (Medestea SpA) (product A) or a $5 \mathrm{mg}$ tablet (1 per os) of Melatonin (SIRC) (product B), according to the randomization schedule, including a washout period of one week.

At each visit, concomitant medication, physical examination, dispensing of study medication, collection of PK blood samples, and adverse events were registered. The two products were administered in the morning under fasting conditions (for at least 12 hours). For the evaluation of melatonin plasma concentrations, $6-8 \mathrm{~mL}$ of blood were collected by venipuncture at time 0 , predose, and at $5,10,20,30$, $40,60,90,120,180,240$, and 360 minutes (min) after administration of each preparation. Blood samples were collected in heparinized disposable tubes. After centrifugation, resulting plasma samples were stored at $-80^{\circ} \mathrm{C}$ until analyzed by liquid chromatography tandem mass spectrometry (LC/MS/MS) [13].

\section{Determination of plasma melatonin concentrations}

Chemicals: A Melatonin reference standard was obtained from Sigma Aldrich (Milan, Italy), N-Acetyltryptamyne an Internal Standard (IS) reference was obtained from Space (Milan, Italy).

All solvents were of HPLC grade or higher. Acetonitrile, Propan- 2-ol, Methanol, Formic Acid were obtained from Carlo Erba (Milan, Italy); Ammonium Formiate from Fluka (Milan, Italy); purified water from Direct-Q, Millipore system (Malsheim, France). A pool of human plasma was obtained from the Department of Transfusion Medicine, Fondazione IRCCS Policlinico San Matteo, Pavia (Italy).

Chromatographic conditions: Melatonin plasma concentrations were detected by reverse phase high performance liquid chromatography, coupled with a tandem mass spectrometer (HPLCMS/MS).

A TSQ Quantum Access spectrometer (Thermo Scientific, San Jose, CA, USA), equipped with an Electrospray Ion Source (ESI), operating in positive mode, was employed for all analyses, in the selected reaction monitoring assay (SRM). The observed transitions (precursor $\rightarrow$ product ions) were: $m / z 233 \rightarrow 173.99$ for Melatonin and $m / z 203 \rightarrow 144.03$ for the Internal Standard. Signals were resolved chromatographically $\left(t_{R}\right.$ $2.78 \mathrm{~min}$ and $3.06 \mathrm{~min}$ respectively) using a Gemini - NX $3 \mu \mathrm{C} 18$ $110 \mathrm{~A}, 100 \times 4.6 \mathrm{~mm}$ column (Phenomenex) and a gradient elution with two mobile phases (A: purified water - Ammonium Formiate $2 \mathrm{mM}$ $\mathrm{HCOOH} 0.1 \%$; $\mathrm{B}: \mathrm{CH}_{3} \mathrm{CN}$ ) at a flow-rate of $650 \mu \mathrm{L} / \mathrm{min}$. The column oven was maintained at $30^{\circ} \mathrm{C}$ and the autosampler tray at $15^{\circ} \mathrm{C}$.

Sample preparation: $50 \mu \mathrm{L}$ aliquots of working solutions of melatonin were added to $450 \mu \mathrm{L}$ of human plasma/water (blank) in 1.5 $\mathrm{mL}$ polypropylene tubes, to yield the final concentrations reported in standard samples and quality controls (QC).

Seven different standard concentrations were used for the calibration curve ranging from $0.156 \mathrm{ng} / \mathrm{mL}$ to $10 \mathrm{ng} / \mathrm{mL}$. To calculate sample concentrations above $10 \mathrm{ng} / \mathrm{mL}$, the calibration curve was extended to $50 \mathrm{ng} / \mathrm{mL}$. A calibration curve was analyzed with each batch. Quality control samples were prepared at the following concentrations: $0.5,4,8$ and $25 \mathrm{ng} / \mathrm{mL}$. Three sets of QC samples were assayed with each run [14].

In brief, $50 \mu \mathrm{L}$ of IS $(20 \mathrm{ng} / \mathrm{mL}$ ), $50 \mu \mathrm{L}$ of $10 \%$ Ammonium Hydroxide solution were added to each standard/unknown sample $(500 \mu \mathrm{L})$, followed by a liquid-liquid extraction with $2 \mathrm{~mL}$ of dichloromethane.

Samples were vortex mixed. Tubes were then centrifuged for 10 min at $3000 \mathrm{~g}$ at $4^{\circ} \mathrm{C}$ and the lower organic phase was transferred into conical glass tubes and evaporated to dryness under a gentle stream of nitrogen at room temperature. Residues were reconstituted in $100 \mu \mathrm{L}$ of acidified water $(\mathrm{HCOOH} 0.1 \%)$ and transferred into a micro-vial. Aliquots of $10 \mu \mathrm{L}$ were injected into the HPLC-MS/MS apparatus and then analyzed.

Pharmacokinetic and statistical analysis: No pharmacokinetic model has been hypothesized, and the following parameters were determined from the measured data:

$\mathrm{C}_{\text {max }}=$ peak plasma concentration $(\mathrm{ng} / \mathrm{ml})$;

$\mathrm{T}_{\max }=$ Time relative to the peak concentration ( $\mathrm{min}$ );

$\mathrm{AUC}_{0-\infty}=$ Area Under the Curve plasma concentration - time curve from 0 to $\infty\left(\mathrm{ng}^{\star} \mathrm{min} / \mathrm{ml}\right)$, calculated by using the linear trapezoidal rule (Kinetica TM Software version 4, InnaPhase Corporation Philadelphia PA);

$\mathrm{F}(\mathrm{A} / \mathrm{B})=$ Relative bioavailability of product $\mathrm{A}$ versus product $\mathrm{B}$;

MRT $=$ Mean Residence Time (min); 
Citation: Bartoli AN, De Gregori S, Molinaro M, Broglia M, Tinelli C, et al. (2012) Bioavailability of a New Oral Spray Melatonin Emulsion Compared with a Standard Oral Formulation in Healthy Volunteers. J Bioequiv Availab 4: 096-099. doi:10.4172/jbb.1000120

$\mathrm{T}_{1 / 2}=$ elimination half-life (min).

We considered $\mathrm{AUC}_{0-\infty}$ as the true estimate of the relative bioavailability $\mathrm{F}$ of melatonin, obtained by comparing AUC from time 0 to $\infty\left(\mathrm{AUC}_{0-\infty}\right)$.

For the estimation of the absorption rate constant $\left(\mathrm{K}_{\mathrm{a}}\right)$ an one compartment open model with oral absorption was hypothesized.

Power consideration: the primary endpoint was to compare the AUC of two formulations of oral melatonin. We hypothesized that after sublingual administration, the amount of melatonin delivered to the general circulation might be much higher, about $50 \%$ or more, than after oral administration. A two sided t-test achieves $84 \%$ power to infer the mean ratio is not 1.000 when the total sample size of a $2 \times 2$ cross-over design is 8 , the actual mean ratio is 1.550 , the coefficient of variation is 0.250 and significant level is 0.0500 .

The mean and standard deviation [SD] were used to summarize quantitative variables. Parametric or non parametric tests were used according data distribution (Shapiro's Test). To evaluate the differences between the two products, $\mathrm{AUC}_{0-\infty}$ and $\mathrm{C}_{\max }$, (after log transformation) were analyzed by the Student $t$ Test for Paired Data. $\mathrm{T}_{\max }$ difference was tested by the Wilcoxon signed-rank test.

$\mathrm{P}<0.05$ was considered statistically significant. All tests were twosided. Data analysis was performed with the STATA statistical package (release 9.0, 2006, Stata Corporation, College Station, Texas, USA).

\section{Results}

\section{Subjects}

Eight subjects were enrolled and completed the study.

Table 1 summarizes demographic and baseline characteristics of the healthy enrolled volunteers.

Table 2 describes mean plasma concentrations after administration of Melatonin in emulsion spray (product A) and Melatonin tablet (product B).

\section{LC/MS/MS}

Regression analysis with the weighted linear regression method $(1 / \mathrm{X})$ was used to obtain the best fit of data for the calibration curves. The curve for all accepted runs had an $r^{2} \geq 0.9896$. The lower limit of quantification (LLOQ) for melatonin was $0.156 \mathrm{ng} / \mathrm{mL}$ and the upper limit of quantification was $50 \mathrm{ng} / \mathrm{mL}$. In all curves, the non-zero standards were within $\pm 15 \%$ of their nominal value in accordance with the acceptance criteria. The LLOQ samples were within $\pm 20 \%$ of their nominal value, inter-assay precision was $9.25 \%$ and inter-assay accuracy was $102.81 \%$, in accordance with the acceptance criteria. For the QC standards, the inter assay-accuracy ranged from $97.58 \%$ to $103.84 \%$ and the inter-assay precision was $\leq 6.72 \%[14]$.

\begin{tabular}{|c|c|c|c|c|}
\hline & Mean & $\begin{array}{c}\text { Standard } \\
\text { Deviation }\end{array}$ & Median & Min-Max \\
\hline Age (years) & 37 & 13 & 44 & $21-51$ \\
\hline Weight $(\mathrm{kg})$ & 71 & 14 & 70 & $54-94$ \\
\hline Height (cm) & 171 & 10 & 165 & $163-190$ \\
\hline Sex (M/F) & $5 / 3$ & & & \\
\hline
\end{tabular}

Table 1: Baseline demographics of the 8 healthy volunteers.

\begin{tabular}{|c|c|c|c|c|c|c|}
\hline & \multicolumn{3}{|c|}{ Product A } & \multicolumn{3}{c|}{ Product B } \\
\hline $\begin{array}{c}\text { Time } \\
\text { min }\end{array}$ & $\begin{array}{c}\text { Mean } \\
\mathrm{ng} / \mathrm{mL}\end{array}$ & SD & Median & $\begin{array}{c}\text { Mean } \\
\mathrm{ng} / \mathrm{mL}\end{array}$ & SD & Median \\
\hline 0 & $\mathbf{0 . 3 8}$ & 0.47 & 0.27 & $\mathbf{0 . 0 0}$ & 0.00 & 0.00 \\
\hline 5 & $\mathbf{1 . 0 9}$ & 0.85 & 0.75 & $\mathbf{0 . 2 9}$ & 0.26 & 0.22 \\
\hline 10 & $\mathbf{4 . 7 9}$ & 3.87 & 3.11 & $\mathbf{3 . 2 1}$ & 3.84 & 1.64 \\
\hline 20 & $\mathbf{1 0 . 4 4}$ & 7.20 & 7.74 & $\mathbf{7 . 0 1}$ & 5.24 & 6.56 \\
\hline 30 & $\mathbf{1 3 . 0 8}$ & 6.29 & 11.23 & $\mathbf{9 . 0 9}$ & 4.36 & 9.43 \\
\hline 40 & $\mathbf{1 3 . 1 4}$ & 5.97 & 11.10 & $\mathbf{1 0 . 6 2}$ & 5.65 & 10.66 \\
\hline 60 & $\mathbf{1 1 . 4 3}$ & 4.73 & 11.78 & $\mathbf{9 . 4 1}$ & 7.04 & 7.97 \\
\hline 90 & $\mathbf{8 . 5 2}$ & 5.61 & 6.85 & $\mathbf{6 . 5 5}$ & 5.09 & 5.57 \\
\hline 120 & $\mathbf{6 . 5 8}$ & 4.70 & 4.71 & $\mathbf{4 . 7 7}$ & 3.65 & 3.99 \\
\hline 180 & $\mathbf{3 . 3 1}$ & 3.17 & 1.92 & $\mathbf{1 . 7 6}$ & 1.61 & 1.44 \\
\hline 240 & $\mathbf{1 . 6 6}$ & 2.09 & 0.55 & $\mathbf{0 . 7 2}$ & 0.58 & 0.67 \\
\hline 360 & $\mathbf{0 . 3 9}$ & 0.48 & 0.21 & $\mathbf{0 . 1 8}$ & 0.15 & 0.21 \\
\hline
\end{tabular}

\begin{tabular}{|c|c|c|}
\hline \multicolumn{3}{|c|}{ Product A } \\
\hline Parameters & $\begin{array}{l}\text { Arithmetic Mean } \\
\text { mean [SD] }\end{array}$ & Range \\
\hline $\mathrm{AUC}_{0-\infty}\left(\mathrm{ng}^{*} \mathrm{~min} / \mathrm{mL}\right)$ & 1719.93 [918.47] & $761.49-3167.70$ \\
\hline $\mathrm{C}_{\max }(\mathrm{ng} / \mathrm{mL})$ & $17.2[9.3]$ & $7.4-37.4$ \\
\hline $\mathrm{T}_{\max }(\min )$ & $42.5[24.9]$ & $20.0-90.0$ \\
\hline $\mathrm{T}_{1 / 2}(\min )$ & $54.0[9.6]$ & $45.3-75.6$ \\
\hline $\mathrm{K}_{\mathrm{a}}\left(\min ^{-1}\right)$ & $0.0311[0.0188]$ & $0.0127-0.0656$ \\
\hline MRT (min) & $57.2[18.2]$ & $32.0-86.3$ \\
\hline \multicolumn{3}{|c|}{ Product B } \\
\hline $\mathrm{AUC}_{0-\infty}\left(\mathrm{ng}^{*} \mathrm{~min} / \mathrm{mL}\right)$ & 1179.23 [776.80] & $232.84-2579.90$ \\
\hline $\mathrm{C}_{\max }(\mathrm{ng} / \mathrm{mL})$ & $12.4[6.6]$ & $3.6-22.9$ \\
\hline $\mathrm{T}_{\max }(\min )$ & $37.5[11.7]$ & $20.0-60.0$ \\
\hline $\mathrm{T}_{1 / 2}(\min )$ & $51.9[13.4]$ & $34.0-69.1$ \\
\hline $\mathrm{K}_{\mathrm{a}}\left(\min ^{-1}\right)$ & $0.0233[0.0049]$ & $0.0176-0.0293$ \\
\hline MRT (min) & $51.6[13.8]$ & $33.4-72.9$ \\
\hline \multicolumn{3}{|c|}{ Ratio A/B } \\
\hline Variable & mean [SD] & Range \\
\hline $\mathrm{AUC}_{0-\infty}\left(\mathrm{ng}^{*} \min / \mathrm{mL}\right)$ & $1.86[1.17]$ & $0.87-4.07$ \\
\hline $\mathrm{C}_{\max }(\mathrm{ng} / \mathrm{mL})$ & $1.5[0.5]$ & $0.9-2.5$ \\
\hline
\end{tabular}

Table 3: Pharmacokinetic parameters of Melatonin in emulsion spray Product $A$ and Melatonin tablet Product B (8 subjects; dose $5 \mathrm{mg}$ )

\section{Pharmacokinetic and statistical results}

The mean and standard deviation values of $\mathrm{AUC}_{0-\infty}, \mathrm{C}_{\max }, \mathrm{T}_{\max }, \mathrm{T}_{1 / 2}$, $\mathrm{K}_{\mathrm{a}}$ and MRT are shown in table 3.

Figure 1 shows the disposition of melatonin after administration of product A (Test Preparation), or product B (Reference Preparation) and the average curves of plasma concentration-time as a result of product $\mathrm{A}$ or product $\mathrm{B}$.

The mean $\mathrm{AUC}_{0-\infty}[\mathrm{SD}]$ were 1719.93 [918.47] $\left(\mathrm{ng}^{\star} \mathrm{min} / \mathrm{mL}\right)$ and 1179.23 [776.80] $\mathrm{ng}^{\star} \mathrm{min} / \mathrm{mL}$ for product $\mathrm{A}$ and $\mathrm{B}$, respectively.

Significant differences were observed in $\mathrm{AUC}_{0-\infty}$ values obtained after treatment with A and B $(\mathrm{P}=0.0446)$.

The ratio $\mathrm{F}(\mathrm{A} / \mathrm{B})$, between the $\mathrm{AUC}_{0-\infty}$ values obtained after 

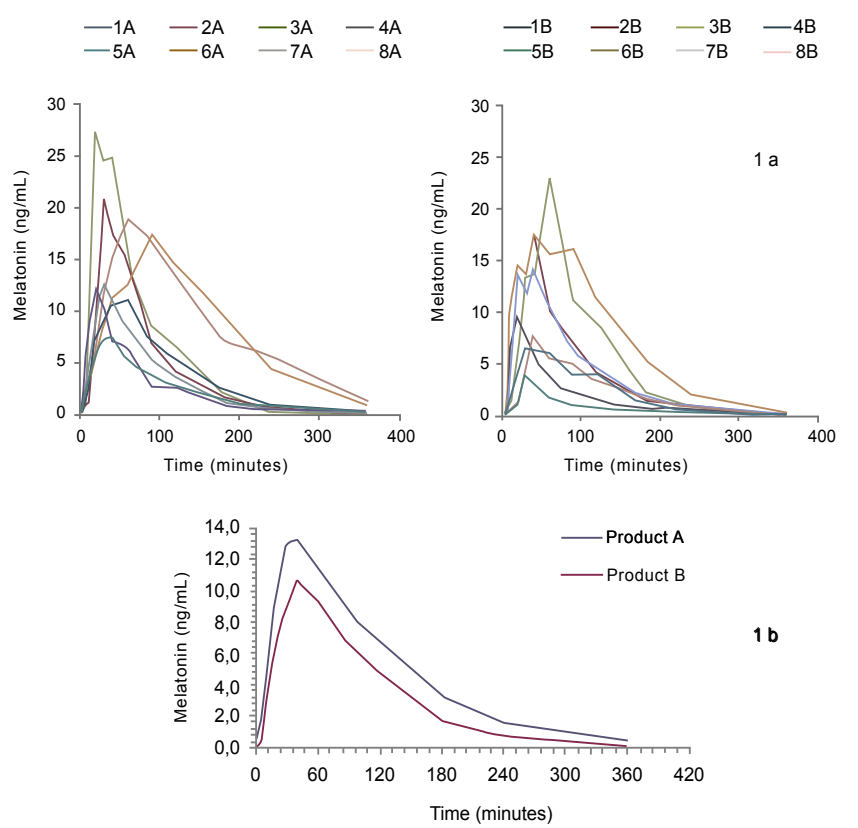

Figure 1: Disposition of Melatonin after administration of Product A or B (pane 1a). Mean (8 subjects) Plasma Concentration-Time Curves (panel 1b).

administration of product A or product B was 1.86 [1.17], when considering the arithmetic mean.

The mean $\mathrm{C}_{\max }$ obtained after administration of product $\mathrm{A}$ or product B was $17.2[9.3] \mathrm{ng} / \mathrm{mL}$ and $12.4[6.6] \mathrm{ng} / \mathrm{mL}$, respectively. Significant differences were observed in $\mathrm{C}_{\max }$ values obtained after treatment with $\mathrm{A}$ or $\mathrm{B}(\mathrm{P}=0.0210)$. The concentration peak for melatonin was obtained at 42.5 [24.9] and 37.5 [11.7] $\mathrm{min}\left(\mathrm{T}_{\max }\right)$ for product $\mathrm{A}$ and product $\mathrm{B}$, respectively. The difference was not statistically significant $(\mathrm{P}=0.7227)$.

\section{Safety}

The preparations and the study treatments were well tolerated without any adverse reactions.

\section{Discussion}

Melatonin is a good candidate for sublingual administration, considering its variable oral absorption, short biological half-life and extensive first pass metabolism. With oral melatonin doses of 2-4 mg, only $15 \%$ of the dose reaches the systemic circulation [15].

Alternatively, oral mucosa absorption avoids the first-pass effect, associated with liver metabolism of melatonin. In general compounds that come in contact with the mucous membrane quickly diffuse through it, since the connective tissue beneath the epithelium is highly vascularized.

This special spray emulsion, showed improvement in most of the issues that have so far hampered the clinical efficacy of melatonin.

The current study characterized the bioavailability of a new oral spray formulation of melatonin in comparison with a standard oral formulation.

The AUC values obtained following a single dose of the two preparations showed significant differences. The amount of melatonin reaching the systemic circulation after administration of oral spray melatonin was significantly higher than that of the oral tablet formulation.
Data obtained in this study showed that the extent of melatonin absorption after oral spray delivery was 1.8 times that observed after administration of the standard oral tablet; the peak concentration was also significantly higher, 1.5 times the corresponding oral tablet value. The absorption rate expressed as $\mathrm{T}_{\max }$ and $\mathrm{K}_{\mathrm{a}}$ was comparable between the two products. After administration of product A (Melatonin in emulsion spray) concentrations of melatonin at 5, 10, and $20 \mathrm{~min}$ respectively were 4.6, 3.5, 3.0 times higher than the corresponding concentrations of product B (Melatonin tablet). Thereafter, the concentrations of melatonin after administration of product $A$ were 1.5-2.4 times the corresponding concentrations of product $B$.

Product A (Melatonin spray) in emulsion and the reference preparation, Product B, (Melatonin tablet) were not super imposable in terms of extent of absorption.

The present study indicates that the new formulation Melatonin food supplement in emulsion spray improves melatonin absorption, ensuring higher concentrations after administration, compared to the standard oral tablet formulation of melatonin.

\section{References}

1. Kaplan H, Sadock B (1985) Modern synopsis of comprehensive textbook of psychiatry IV William \& Wilkens Baltimore 558-574.

2. Nir I (2003) Melatonin for the treatment of disorders in circadian rhythm and sleep: could it form a basis for medication? Receptors Channels 9: 379-385.

3. Wetterberg L, Bergiannaki JD, Paparrigopoulos T, von Knorring L, Eberhard G, et al. (1999) Normative melatonin excretion: a multinational study. Psychoneuroendocrinology 24: 209-226.

4. Ohayon MM, Carskadon MA, Guilleminault C, Vitiello MV (2004) Metaanalysis of quantitative sleep parameters from childhood to old age in healthy individuals: developing normative sleep values across the human lifespan. Sleep 27: 1255-1273.

5. Altun A, Ugur-Altun B (2007) Melatonin: therapeutic and clinical utilization. Int J Clin Pract 61: 835-845.

6. Navara KJ, Nelson RS (2007) The dark side of light at night: Physiological epidemiological and ecological consequences. J Pineal Res 43: 215-224.

7. EFSA (2010) EFSA panel on dietetic products, nutrition, and allergies (NDA) EFSA Journal.

8. Jan JE, Reiter RJ, Wasdell MB, Bax M (2009) The role of the thalamus in sleep, pineal melatonin production, and circadian rhythm sleep disorders. J Pineal Res 46: 1-7.

9. Arendt J, Deacon S (1997) Treatment of circadian rhythm disorders--melatonin Chronobiol Int 14: 185-204.

10. Perreau-Lenz S, Pevet P, Buijs RM, Kalsbeek A (2004) The biological clock: the bodyguard of temporal homeostasis. Chronobiol Int 21: 1-25.

11. Gooneratne NS, Edwards AY, Zhou C, Cuellar N, Grandner MA, et al. (2012) Melatonin pharmacokinetics following two different oral surge-sustained release doses in older adults. J Pineal Res 52: 437-445.

12. Calpena AC, Clares B, Fernandez F (2011) Technological, biopharmaceutical and pharmacokinetic advances: new formulations of application on the skin and oral mucosa. Recent Advances in Pharm Sciences 175-198.

13. Wang AQ, Wei BP, Zhang Y, Wang YJ, Xu L, et al. (2011) An ultra-high sensitive bioanalytical method for plasma melatonin by liquid chromatographytandem mass spectrometry using water as calibration matrix. J Chromatogr B Analyt Technol Biomed Life Sci 879: 2259-2264.

14. The guidance for Industry "Bioanalytical Method Validation "issued by FDA on May 2001.

15. DeMuro RL, Nafziger AN, Blask DE, Menhinick AM, Bertino JS Jr (2000) The absolute bioavailability of oral melatonin. J Clin Pharmacol 40: 781-784. 